\title{
Adhesion of cast metal alloy and lithium disilicate copings luted to different core build-up materials with self-adhesive resin cement
}

Al-Dwairi, Ziad Nawaf ; Aleisa, Khalil ; Al-Beshr, Abdulhameed ; Al-Habdan, Yazeed ; Al-Harbi, Faisal ; Al-Haj Husain, Nadin ; Özcan, Mutlu

Abstract: This study evaluated the shear bond strength of two coping materials (non-nickel chrome-based cast alloy and lithium disilicate ceramic (IPS Empress) to four different core foundation materials (resin composite, cast metal alloy, lithium disilicate, and dentin), luted with adhesive resin cement (RelyX Unicem). Specimens $(\mathrm{N}=56)$ were fabricated and divided into eight groups $(\mathrm{n}=7$ per group). Each coping material was luted with self-adhesive resin cement (RelyX Unicem) to the core materials. Bond strength was measured in a Universal Testing Machine $(0.5 \mathrm{~mm} / \mathrm{min})$. Data were statistically analyzed using a two-way analysis of variance (ANOVA) and Tukey's HSD tests (alpha $=0.05)$. Both core $(p=0.000)$ and coping material type $(p=0.000)$ significantly affected the mean bond strength $(\mathrm{MPa})$ values. Interaction terms were also significant $(\mathrm{p}=0.001)$. The highest bond strength results were obtained when lithium disilicate was bonded to lithium disilicate (21.48) with the resin cement tested. Lithium disilicate in general presented the highest bond results when bonded to all core materials tested (16.55-21.38) except dentin (3.56). Both cast alloy (2.9) and lithium disilicate (3.56) presented the lowest bond results on dentin followed by cast-alloy-cast alloy combination (3.82).

DOI: https://doi.org/10.1080/01694243.2016.1208997

Posted at the Zurich Open Repository and Archive, University of Zurich

ZORA URL: https://doi.org/10.5167/uzh-146613

Journal Article

Accepted Version

Originally published at:

Al-Dwairi, Ziad Nawaf; Aleisa, Khalil; Al-Beshr, Abdulhameed; Al-Habdan, Yazeed; Al-Harbi, Faisal; Al-Haj Husain, Nadin; Ȯzcan, Mutlu (2017). Adhesion of cast metal alloy and lithium disilicate copings luted to different core build-up materials with self-adhesive resin cement. Journal of Adhesion Science and Technology, 31(3):242249.

DOI: https://doi.org/10.1080/01694243.2016.1208997 
Adhesion of cast metal alloy and lithium disilicate copings luted to different core build-up materials with self-adhesive adhesive resin cement

Ziad Nawaf Al-Dwairi, BDS, PhD, FIADFEa / Khalil Aleisa, BDS, MSc ${ }^{\text {b }}$ Abdulhameed Al-Beshr, BDSc/ Yazeed Al-Habdan, BDSc/ Faisal Al-Harbi, BDSc / Nadin Al-Haj

\author{
Husain, MDent Med ${ }^{\mathrm{d}} /$ \\ Mutlu Özcan, DDS, DMD, PhDe
}

aProfessor, Department of Prosthodontics, Faculty of Dentistry, Jordan University of Science and Technology, Irbid, Jordan

${ }^{b}$ Professor, Department of Prosthetic Dental Sciences, College of Dentistry, King Saud University, Riyadh, Saudi Arabia

cIntern, College of Dentistry, King Saud University, Riyadh, Saudi Arabia

${ }^{d}$ Doctorate student, University of Zurich, Dental Materials Unit, Center for Dental and Oral Medicine, Clinic for Fixed and Removable Prosthodontics and Dental Materials Science, Zurich, Switzerland

eProfessor, University of Zurich, Dental Materials Unit, Center for Dental and Oral Medicine, Clinic for Fixed and Removable Prosthodontics and Dental Materials Science, Zurich, Switzerland

Short title: Adhesion of cast metal alloy and lithium disilicate copings

Correspondance to: Prof. Ziad Nawaf Al- Dwairi, BDS, PhD, FIADFE, Department of Prosthodontics, Faculty of Dentistry, Jordan University of Science and Technology, Irbid, Jordan. E-mail: ziadd@just.edu.jo 
Abstract: This study evaluated the shear bond strength of two coping materials (nonnickel chrome based cast alloy and lithium disilicate ceramic (IPS Empress) to four different core foundation materials (resin composite, cast metal alloy, lithium disilicate and dentin), luted with adhesive resin cement (RelyX Unicem). Specimens ( $N=56)$ were fabricated and divided into 8 groups ( $n=7$ per group). Each coping material was luted with self-adhesive resin cement (RelyX Unicem) to the core materials. Bond strength was measured in a Universal Testing Machine $(0.5 \mathrm{~mm} / \mathrm{min})$. Data were statistically analyzed using a two-way analysis of variance (ANOVA) and Tukey`s HSD tests (alpha=0.05). Both core $(p=0.000)$ and coping material type $(p=0.000)$ significantly affected the mean bond strength $(\mathrm{MPa})$ values. Interaction terms were also significant $(\mathrm{p}=0.001)$. The highest bond strength results were obtained when lithium disilicate was bonded to lithium disilicate (21.48) with the resin cement tested. Lithium disilicate in general presented the highest bond results when bonded to all core materials tested (16.55-21.38) except dentin (3.56). Both cast alloy (2.9) and lithium disilicate (3.56) presented the lowest bond results on dentin followed by cast-alloy-cast alloy combination (3.82).

Keywords: Adhesion; cast metal; lithium disilicate; resin cement 


\section{Introduction}

In most situations, severely compromised teeth due to caries or trauma are restored with complete coverage crowns to restore function and aesthetics in dentistry. In pulpless teeth, the amount of the remaining tooth structure dictates the need and type of core build-up material that serves as a foundation to hold the crown in place. In case of minimal loss of structure, root posts and cores are not necessary [1]. However, when a horizontal loss of the clinical crown is present, resulting from caries, trauma or the previous restoration, a small ferrule can be created in the remaining tooth structure and restored with root post and core build-up with different materials [2-4].

A core build-up should be able to withstand axial and lateral loads and must contribute to the retention and support of both a provisional crown and, in the long term, the definitive extra-coronal restoration where the choice of core material is a crucial factor in the success of the restoration [5]. Core materials used in dentistry have included amalgam, resin composites, glass-ionomers and ceramics [6-13].

Core material type and dentin can affect the adhesion of crown materials cemented with luting cement to these substrates. The clinical success of dental restorations is profoundly dependent on the luting cement and the cementation procedures [14]. Dental luting agents should both increase retention of the restoration and maintain its integrity on the dental tissues. In recent years, resin cements have gained popularity because of their advanced physical properties, high mechanical strength and chemical adherence to tooth substance, resin composites as well as ceramics [15]. Adhesive properties of cements are significantly important for the stability of restorative materials, especially for teeth with limited retention. Therefore, it is essential to achieve adequate bond of the resin cement to the restorative, core material and the dentin. Selection of core and coping materials depends on the needs for strength, biocompatibility and aesthetics [16]. To the best of the authors' knowledge, no 
study addressed the adhesion between different core and crown materials luted with adhesive resin cement.

The objective of this study therefore was to evaluate the adhesion of two coping materials (cast metal alloy and lithium disilicate ceramic to four different core foundation materials (resin composite, cast metal alloy, lithium disilicate ceramic and dentin), luted with self-adhesive resin cement. The null hypothesis tested was that neither the crown nor core material would significantly affect the adhesion results.

\section{Materials and Methods}

Specimens $(\mathrm{N}=56)$ were fabricated and divided into 8 groups consisting of 7 specimens each with different core and coping material combinations (Table 1).

Preparation of core materials

A silicon mould (Aquasil Ultra LV, Dentsply, Milford, DE, USA) (diameter: $10 \mathrm{~mm}$, height: 3 $\mathrm{mm}$ ) was made to fabricate the cores made of resin composite, cast metal and all ceramic. Resin composite group

Resin based core build-up material (Multicore, Ivoclar Vivadent, Schaan, Liechtenstein) was injected directly from the syringe tip into the cavity of the silicon mould. A glass slab was placed on the top and bottom of the mould and the resin was photo-polymerized $(X L$ 2500, 3M ESPE, St. Paul, MN, USA) for $40 \mathrm{~s}$.

Cast metal alloy group

Blue inlay wax (Ivoclar Vivadent, NY, USA) was melted and poured in the silicon mould and left to set for 1 hour for further processing. The resultant disc of wax was connected to a wax sprue (Bego, Bremer Goldschlägerei Wilh. Herbst GmbH Co. KG, Bremen, Germany) and invested in a phosphate-bonded investment (Multi-Vest, Dentsply International, York, PA, USA) mixed under vacuum for 1 minute. After 1 hour setting time, 
the specimens were placed in an oven for burn out (Accu-Therm II 250, Heraeus Kulzer, South Bend, IN, USA) and gradually heated up to $800^{\circ} \mathrm{C}$. All specimens were cast at (950$\left.1000^{\circ} \mathrm{C}\right)$ in a centrifugal casting machine (74 Exact-U-Cast, Handler, Westfield, NJ, USA) using non-precious nickel chrome based metal alloy (Vera Bond II, Aalba Dent, Fairfield, CA, USA), divested and airborne-particle abraded (Miniblaster, Belle de St. Claire, Encino, $\mathrm{CA}, \mathrm{USA}$ ) using $50 \mu \mathrm{m}$ aluminum oxide (Strahlmittel, abrasives, Renfert $\mathrm{GmbH}$, Hilzingen, Germany) at 60 psi (Easy Blast, Bego, Bremen, Germany) for $15 \mathrm{~s}$ in order to remove the residual investment material. The sprues were cut off with metal discs (Dentarium International Inc., New York, NY, USA) and were finished using diamond bur (3069 diamond bur, KG Sorensen, Sao Paulo, Brazil).

Lithium disilicate group

Wax patterns were invested (IPS Empress Investment, Ivoclar Vivadent) and heat pressed using lost wax technique. After the burn out and preheating process, the core material (Empress-Cosmo, Ivoclar Vivadent, Lot no: D64021) was pressed at $900^{\circ} \mathrm{C}$ at 5 bar pressure. The core discs were divested and specimen surfaces were carefully airborneparticle abraded (Miniblaster) using $50 \mu \mathrm{m}$ aluminum oxide particles at a pressure of 80 psi.

\section{Dentin group}

After removal of debris, human sound extracted premolars were sectioned $2 \mathrm{~mm}$ coronal to the most incisal point of the cemento-enamel junction (CEJ) with a low speed diamond saw (Isomet 2000, Buehler Ltd, Lake Bluff, NY) under copious water cooling. Buccal enamel surfaces of all teeth were totally removed perpendicular to the long axis of the tooth using water-cooled cylindrical diamond (\#837-016, SSwhite, USA). Then, the dentin surfaces were prepared with 240, 400, and 600 grit silicon carbide papers (Matador, Germany) in sequence under copious water. 
Finally, the specimens were mounted in auto-polymerizing resin (Ortho Resin, Dentsply DeTrey Gmbh, Konstanz, Germany) in polyvinyl chloride moulds (diameter: $18 \mathrm{~mm}$; height: $25 \mathrm{~mm}$ ) with their cementation surfaces exposed.

Preparation of coping materials

Cast metal alloy

Bar-shaped wax (Gebdi Dental Products $\mathrm{GmbH}$, Engen, Germany) (diameter: $4 \mathrm{~mm}$; thickness: $5 \mathrm{~mm}$ ) specimens were connected to a wax sprue (Bego, Bremer Goldschlägerei Wilh. Herbst GmbH Co. KG), and invested in a phosphate-bonded investment material (Multi-Vest, Dentsply International, York, PA, USA) that was mixed under vacuum for 1 minute. After 1 hour setting time, the specimens were placed in the oven (Accu-Therm II 250) for burn out and gradually heated up to $800^{\circ} \mathrm{C}$. All specimens were cast at $\left(950-1000^{\circ} \mathrm{C}\right)$ in a centrifugal casting machine (74 Exact-U-Cast, Handler, Westfield, NJ) using non-precious nickel chrome based metal alloy (Vera Bond II, Aalba Dent, Fairfield, CA, USA). Then, specimens were divested and airborne-particle abraded (Miniblaster, Belle de St. Claire) using $50 \mu \mathrm{m}$ aluminum oxide (Strahlmittel abrasives, Renfert $\mathrm{GmbH}$ ) at $60 \mathrm{psi}$ (Easy Blast, Bego, Bremen, Germany) for $15 \mathrm{~s}$ in order to remove the residual investment material. The sprues were cut off with metal discs (Dentarium International Inc., New York, NY, USA) and were finished using diamond bur (3069 diamond bur, KG Sorensen, Sao Paulo, Brazil).

Lithium disilicate group

The specimens in this group were prepared using the identical protocol described for lithium disilicate group described under core materials.

Cementation

Lithium disilicate specimens were etched using hydrofluoric acid (Ultradent Products, Inc, South Jordan, UT, USA) for 1 minute, washed and rinsed thoroughly. 
Each coping specimen was luted to the corresponding core specimen using selfadhesive resin cement (RelyX Unicem, 3M ESPE, St. Paul, MN, USA) according to the manufacturer's instructions. The cement capsule was activated for $2 \mathrm{~s}$ and mixed automatically in a high-speed mixed (Ultramet 2, SDI Limited, Bayswater, Victoria, Australia) for $10 \mathrm{~s}$. Thereafter, resin cement was applied on the coping surface and placed on the core surface under finger pressure. Excess cement was removed from the core surface using microbrush. Bonded core-coping assemblies were photo-polymerized from a distance of $3 \mathrm{~mm}$ using halogen polymerizing unit (Astralis 10, Ivoclar Vivadent) at 750 $\mathrm{mW} / \mathrm{cm}^{2}$ for $40 \mathrm{~s}$ from 4 directions each.

Specimens were stored in water at $37^{\circ} \mathrm{C}$ for $24 \mathrm{~h}$ prior to tests.

Bond strength test

Shear bond strength testing was carried out in Universal Testing Machine (Instron, Model 8500 Plus Dynamic Testing System, Instron Corp., High Wycombe, UK) at a cross-head speed of $0.5 \mathrm{~mm} / \mathrm{min}$. Bonded core-coping interfaces were loaded axially until debonding. Statistical analysis

Data were analyzed using a statistical software package (SPSS Software V.16, Chicago, IL, USA). Kolmogorov-Smirnov and Shapiro-Wilk tests were used to test normal distribution of the data. As the data were normally distributed, 2-way analysis of variance (ANOVA) was used where bond strength (MPa) was the dependant variable and coping materials (2 levels: cast metal alloy and lithium disilicate ceramic) and core materials (4 levels: resin composite, cast metal alloy, lithium disilicate and dentin) as the independent factors. Multiple comparisons were made using Tukey`s test. $P<0.05$ was considered to be statistically significant in all tests. 


\section{Results}

Both core $(p=0.000)$ and coping material type $(p=0.000)$ significantly affected the mean bond strength $(\mathrm{MPa})$ values. Interaction terms were also significant $(\mathrm{p}=0.001)$ (Table 2$)$.

Within the metal coping groups, significant differences were observed when bonded to metal, composite $(p=0.010)$ and lithium disilicate core materials $(p=0.026)$ (Table 3$)$.

While composite and dentin core materials showed significant difference for both metal $(p=0.003)$ and lithium disilicate coping materials $(p=0.007)$, no significant difference was observed between the metal and dentin core materials $(p=0.945)$ and between lithium disilicate and resin composite core materials $(p=0.978)$.

For the dentin core groups, there was no significant difference in the mean bond strength between the metal and lithium disilicate coping materials $(p=0.538)$.

The highest bond strength results were obtained when lithium disilicate was bonded to lithium disilicate (21.48) with the resin cement tested. Lithium disilicate in general presented the highest bond results when bonded to all core materials tested (16.55-21.38) except dentin (3.56). Both cast alloy (2.9) and lithium disilicate (3.56) presented the lowest bond results on dentin followed by cast-alloy-cast alloy combination (3.82).

\section{Discussion}

The type of core build-up, cement material and core materials affects the survival of extracoronal restorations. This study was undertaken to evaluate the adhesion of two coping materials (cast metal alloy and lithium disilicate ceramic to four different core foundation materials (resin composite, cast metal alloy, lithium disilicate ceramic and dentin), luted with self-adhesive resin cement. Based on the results of this study, since both core and coping material types significantly affected the bond strength values, the null hypothesis could be rejected. 
Within the metal, composite, and lithium disilicate core groups, the results showed significant differences in the mean bond strength when using the metal and lithium disilicate coping materials. However, for the dentin core groups, there was no significant difference between both coping materials. In the present study, self-adhesive resin cement (RelyX Unicem) was used. Self-adhesive cements principally do not require any surface conditioning method such as etching, priming or bonding. Hence they could be used as conventional luting cements on different types of prosthetic core materials [17]. Although, the manufacturer's recommendations of RelyX Unicem do not recommend surface any surface conditioning method prior to the application of the cement, lithium disilicate ceramic specimens were etched with hydrofluoric acid for 1 minute. Previous studies either used hydrofluoric etching and silanization [18] or not [19]. Although controversial protocols are presented in these studies for self-etching luting cements, etching the intaglio surfaces of glassy matrix ceramics and bonding with resin cement increases the flexural strength of such ceramics [20]. The high results obtained with the ceramic group in this study on metal, composite and lithium disilicate cores could evidently be explained by the micromechanical retention created after hydrofluoric acid etching. It also has to be noted that no silane coupling agent was used after hydrofluoric acid etching. Likewise, no alloy primers were used for conditioning cast alloy surfaces after air-abrasion. Hence, the chemical component was absent in adhesion of the resin cement to the substrates.

The other reason for high bond results in the lithium disilicate group could be due to $\underline{\text { better light transmission through this material compared to cast metal alloy that might have }}$ increased polymerization. Yet, apparently, photo-polymerization alone was not sufficient for increasing adhesion on dentin since also in the ceramic group, adhesion to dentin was weak. The reason for this is that the self-adhesive cements do not etch the dentin at the same level as phosphoric acid etching as they usually contain acidic monomers such as 
phosphoric acid esters, MDP, bis-HEMA-phosphate, glycerolphosphate dimethacrylate, 4META, others contain bis-GMA alone or in combination with TEG-DMA with low pH $[21,22]$.

In this study, the highest mean bond strength value was recorded for lithium disilicate coping group (21.5 MPa) was less than previous studies where values in the range of 23$41 \mathrm{MPa}$ [23] and 23-41 $\mathrm{MPa}$ [24] were reported. Nevertheless, the presence of macromechanical retention may offset the adhesion related problems in retention of copings on core materials [25]. Considering that the patients function, immediately after cementation of the restorations, this study assessed immediate bond strength between the $\underline{\text { self-adhesive resin cement and restorative materials. Further studies should also look at }}$ durability of adhesion results obtained in this study after long-term aging on a larger sample.

\section{Conclusions}

From this study, the following could be concluded:

1. Lithium disilicate coping material bonded to the same core material demonstrated the highest bond strength with the self-adhesive resin cement tested.

2. Lithium disilicate and cast alloy coping material showed the lowest results when bonded to dentin, followed by cast alloy coping bonded to cast alloy.

3. On all core materials tested, cast alloy coping delivered lower bond strength compared to lithium disilicate.

\section{Clinical Relevance}

When self-adhesive resin cement (RelyX Unicem) is chosen for luting coping material to core material, the choice of material should be lithium disilicate for both the coping and the 
core, which should be etched with hydrofluoric acid for 1 min prior to bonding. RelyX Unicem cannot be indicated for bonding coping materials on dentin due to low bond strengths obtained.

\section{Acknowledgement}

The authors acknowledge the College of Dentistry Research Center and the Deanship of Scientific Research at King Saud University for the support of this research.

\section{Conflict of interest}

The authors did not have any commercial interest in any of the materials used in this study. 


\section{References}

1. Robbins JW, Earnest LA, Schumann SD. Fracture resistance of endodontically treated cuspids. Am J Dent 1993;6:159-161.

2. Sorensen JA, Engelman MJ. Ferrule design and fracture resistance of endodontically treated teeth. J Prosthet Dent 1990;63:529-536.

3. Libman WJ, Nicholls Jl. Load fatigue of teeth restored with cast posts and cores and complete crowns. Int J Prosthodont 1995;8:155-161.

4. Shillingburg HT, Hobo S, Whitsett LD, et al. Preparations for extensively damaged teeth. In: Fundamentals of fixed prosthodontics. Quintessence 1997, Berlin, pp.181-209.

5. Burke FJT, Shaglouf AG, Combe EC, Wilson WHF. Fracture resistance of five pinretained core build-up materials on teeth with and without extra coronal preparation. Oper Dent 2000;25:388-394.

6. Millstein PL, Nathanson D. Effect of eugenol and eugenol cements on cured composite resin. J Prosthet Dent 1983;50:211-215.

7. Taleghami M, Leinfielder KF. Evaluation of a new glass-ionomer cement with silver as a core build-up under a cast restoration. Quintessence Int 1988;19:19-24 .

8. Kane $\mathrm{JJ}$, Burgess JO. Modification of the resistance form of amalgam coronal-radicular restorations. J Prosthet Dent 1991;65:470-474.

9. Millstein PL, Nathanson D. Retention between a serrated steel dowel and different core materials. J Prosthet Dent 1991;65:480-482.

10. Cohen BI, Pagnillo MK, Newman I, Musikant BL, Deutsch AS. Pilot study of the cyclic fatigue characteristics of five endodontic posts with four core materials. J Oral Rehabil 2000;27:83-92. 
11. Cohen BI, Pagnillo MK, Newman I, Musikant BL, Deutsch AS. Retention of a core material supported by three post head designs. J Prosthet Dent 2000;83:624-628.

12. Gonzales AM, Borras VA, Font AF, Otaolaurruchi ES, Rueda CL. Response of three types of cast posts and cores to static loading. Quintessence Int 2001;32:552-560.

13. De Backer H, Van Maele G, De Moor N, Van Den Berghe L, De Boever J. An 18-year retrospective survival study of full crowns with or without posts. Int $\mathrm{J}$ Prosthodont 2006;19:136-142.

14. Macorra JC, Pradı'es G. Conventional and adhesive luting cements. Clin Oral Investig 2002;6:198-204.

15. Diaz-Arnold AM, Vargas MA, Haselton DR. Current status of luting agents for fixed prosthodontics. J Prosthet Dent 1999;81:135-141

16. Yuichi Kitasako, Michael F. Burrow, Toru Nikaido, Naoko Harada. Shear and tensile bond testing for resin cement evaluation. Dent Mater 1995;11:298-304.

17. Gerth HU, Dammaschke T, Zu“ chner H, Scha" fer E. Chemical analysis and bonding reaction of RelyX Unicem and Bifix composites-a comparative study. Dent Mater 2006;22:934-941.

18. Pisani-Proenca J, Erhardt MC, Valandro LF, Gutierrez-Aceves G, Bolanos-Carmona MV, Del Castillo-Salmeron R, Bottino MA Influence of ceramic surface conditioning and resin cements on microtensile bond strength to a glass ceramic. J Prosthet Dent 2006;96:412-417.

19. Kumbuloglu O, Lassila LV, User A, Toksavul S, Vallittu PK. Shear bond strength of composite resin cements to lithium disilicate ceramics. J Oral Rehabil 2005;32:128-133.

20. Hooshmand T, Rostami G, Behroozibakhsh M, Fatemi M, Keshvad A, van Noort R. Interfacial fracture toughness of different resin cements bonded to a lithium disilicate glass ceramic. J Dent 2012;40:139-145. 
21. Ferracane JL, Stansbury JW, Burke FJ. Self-adhesive resin cements - chemistry, properties and clinical considerations. J Oral Rehabil 2011;38:295-314.

22. Özcan M, Bernasconi M. Adhesion to zirconia used for dental restorations: a systematic review and meta-analysis. J Adhes Dent 2015;17:7-26.

23. Dündar $M$, Özcan $M$, Cömlekoglu E, Güngör MA, Artunç $C$. Bond strengths of veneering ceramics to reinforced ceramic core materials. Int J Prosthodont 2005;18:71-72. 24. Al-Dohan HM, Yaman P, Dennison JB, Razzoog ME, Lang BR. Shear strength of core-veneer interface in bi-layered ceram. J Prosthet Dent 2004;91:349-355.

25. Edelhoff D, Özcan M. To what extent does the longevity of fixed dental prostheses depend on the function of the cement? Working Group 4 materials: cementation. Clin Oral Implants Res 2007;18 Suppl 3:193-204. 


\section{Captions to tables:}

\section{Tables:}

Table 1. Distribution of core and coping materials composing the experimental groups.

Table 2. Results of two-way ANOVA and Tukey's tests.

Table 3. The mean and standard deviations of shear bond strength of the experimental groups. *Same lower case superscript letters indicate no significant difference for cast alloy and same upper case superscript letters indicate no significant difference for lithium disilicate copings bonded on different core materials $(p>0.05)$. 
Tables:

\begin{tabular}{llll}
\hline Core Material & Coping Material & $\begin{array}{l}\text { Group } \\
\text { Numbers }\end{array}$ \\
\hline Resin composite & Lithium disilicate & 1 & Tables: \\
Resin composite & Cast alloy & 2 & \\
Dentin & Lithium disilicate & 3 & \\
Dentin & Cast alloy & 4 & \\
Lithium disilicate & Lithium disilicate & 5 \\
Lithium disilicate & Cast alloy & 6 \\
Cast alloy & Lithium disilicate & 7 \\
Cast alloy & Cast alloy & 8 \\
\hline
\end{tabular}

Table 1. Distribution of core and coping materials composing the experimental groups.

\begin{tabular}{cccccc}
\hline Source & $\begin{array}{c}\text { Type III Sum of } \\
\text { Squares }\end{array}$ & df & $\begin{array}{c}\text { Mean } \\
\text { Square }\end{array}$ & F- value & $\begin{array}{c}\text { P- } \\
\text { Vaue }\end{array}$ \\
\hline Core & 1245.222 & 3 & 415.074 & 22.956 & 0.000 \\
Coping & 1089.376 & 1 & 1089.376 & 60.248 & 0.000 \\
Core $\mathbf{x}$ & 336.344 & 3 & 112.115 & 6.200 & 0.001 \\
Coping & & & & & \\
Error & 867.919 & 48 & 18.082 & & \\
$\quad$ Total & 9970.862 & 56 & & & \\
$\begin{array}{c}\text { Corrected } \\
\text { Total }\end{array}$ & 3538.861 & 55 & & & \\
\hline
\end{tabular}

Table 2. Results of two-way ANOVA and Tukey`s tests. 


\begin{tabular}{|c|c|c|c|}
\hline Core & Coping & Mean (MPa) & $\mathbf{N}$ \\
\hline \multirow{2}{*}{ Cast alloy } & Cast alloy & $3.82 \pm 0.8^{a}$ & 7 \\
\hline & Lithium disilicate & $16.55 \pm 4.9^{\mathrm{A}}$ & 7 \\
\hline \multirow[t]{2}{*}{ Resin composite } & Cast alloy & $9.59 \pm 3.9^{b}$ & 7 \\
\hline & Lithium disilicate & $18.92 \pm 3.3^{\mathrm{A}}$ & 7 \\
\hline \multirow[t]{2}{*}{ Lithium disilicate } & Cast alloy & $8.92 \pm 4.6^{b}$ & 7 \\
\hline & Lithium disilicate & $21.48 \pm 8.1^{A, B}$ & 7 \\
\hline \multirow[t]{2}{*}{ Dentin } & Cast alloy & $2.9 \pm 1.4^{\mathrm{a}}$ & 7 \\
\hline & Lithium disilicate & $3.56 \pm 2.4^{C}$ & 7 \\
\hline \multirow[t]{3}{*}{ Total } & Cast alloy & $6.31 \pm 4.2^{*}$ & 28 \\
\hline & Lithium disilicate & $15.13 \pm 8.5^{* *}$ & 28 \\
\hline & Total & $10.72 \pm 8$ & 56 \\
\hline
\end{tabular}

Table 3. The mean and standard deviations of shear bond strength of the experimental groups. *Same lower case superscript letters indicate no significant difference for cast alloy and same upper case superscript letters indicate no significant difference for lithium disilicate copings bonded on different core materials $(p>0.05)$. 